\title{
Structural and Optical Characterization of Magnesium Doped Zinc Oxide Thin Films Deposited by Spray Pyrolysis
}

\author{
Mitali Biswas ${ }^{1}$, Mehnaz Sharmin ${ }^{2}$, Chitra Das ${ }^{3}$, Jibon Poddar ${ }^{2}$ and Shamima Choudhury ${ }^{1}$ \\ ${ }^{1}$ Department of Physics, Dhaka University, Dhaka-1000, Bangladesh \\ ${ }^{2}$ Department of Physics, Bangladesh University of Engineering and Technology, Dhaka-1000, Bangladesh \\ ${ }^{3}$ Department of Mathematics \& Natural Sciences, BRAC University, Dhaka-1212, Bangladesh
}

(Received: 1 April 2015; Accepted: 1 June 2015)

\begin{abstract}
Pure and magnesium $(\mathrm{Mg})$ doped zinc oxide $(\mathrm{ZnO})$ thin films were prepared onto clean glass substrate by spray pyrolysis (SP) technique at the substrate temperature of $300^{\circ} \mathrm{C}$. Various optical parameters such as absorption co-efficient, band gap energy, refractive index, extinction coefficient of the thin films were studied using UV-VIS-NIR spectrophotometer in the photon wavelength range of $300-2500 \mathrm{~nm}$. Optical band gap increased from 3.24 to $3.46 \mathrm{eV}$ with the increase of $\mathrm{Mg}$ concentration from 0 to $40 \%$. Transmittance and refractive index of the $\mathrm{Mg}$ doped $\mathrm{ZnO}$ thin films decreased due to the increase of $\mathrm{Mg}$ concentration. The EDX spectra confirmed the increase of $\mathrm{Mg}$ and consequent reduction in $\mathrm{Zn}$ content in the $\mathrm{Mg}$ doped $\mathrm{ZnO}$ thin films. Pure and $\mathrm{Mg}$ - doped $\mathrm{ZnO}$ films were annealed at $425^{\circ} \mathrm{C}$ for 1 hour. X-ray diffraction (XRD) study of the annealed films showed hexagonal type of polycry-stalline structure with the preferred orientation along (101) plane with some other peaks (100), (002), (102), (110), (103) and (112). From the XRD patterns it was found that grain size decreased from 63.45 to $36.56 \mathrm{~nm}$, lattice constant $a$ and c remained almost constant with $\mathrm{Mg}$ doping concentration.
\end{abstract}

Keywords: Spray pyrolysis, Mg doped ZnO thin films, band gap energy, XRD analysis, EDX analysis.

\section{Introduction}

In recent years, zinc oxide $(\mathrm{ZnO})$ has been studied extensively by several researchers ${ }^{1-4}$ due to its interesting physical and chemical properties. It is a II-VI compound semiconductor with a direct and wide band gap $(\sim 3.3 \mathrm{eV})$ at room temperature and a large exciton binding energy ( 60 $\mathrm{meV})^{5}$. It is highly transparent in the visible and near infrared region of electromagnetic spectrum and shows high refractive index ${ }^{6}$. Such remarkable optical properties of $\mathrm{ZnO}$ make it useful in short wavelength photonic devices. It is used in UV-light emitting diodes, transparent electrodes, laser diodes, window layers, photovoltaic cells, varistors, thin film transistors, heterojunction solar cells, etc. ${ }^{7,8}$. $\mathrm{ZnO}$ is capable to form alloy with nickel $(\mathrm{Ni})$, cobalt $(\mathrm{Co})$, iron $(\mathrm{Fe})$, magnesium $(\mathrm{Mg})$, cadmium $(\mathrm{Cd})$, etc. Band gap tuning can be achieved in such alloys in thin film form by changing the doping concentration ${ }^{9}, 10 . \mathrm{Mg}$ is one of the popular materials in preparation of doped $\mathrm{ZnO}$ thin films. Because, atomic radius of $\mathrm{Mg}$ is comparable to that of $\mathrm{Zn}$ and lattice distortion occurs by a small amount when $\mathrm{Zn}$ ion is replaced by $\mathrm{Mg}$ ion ${ }^{11,12} \mathrm{ZnO}$ has wurtzite and $\mathrm{MgO}$ has rock salt cubic type of crystal structure. Because of such a mismatch in crystal lattices a difficulty arises during tailoring of band gap in the alloy formed by them. However, several works have been reported on preparation of $\mathrm{Mg}$ doped $\mathrm{ZnO}$ thin films by various techniques and successfully overcome the difficulty. Molecular beam epitaxy (MBE) ${ }^{13}$, chemical vapor deposition (CVD) ${ }^{14}$, Sol-gel ${ }^{15}$, spray pyrolysis (SP) ${ }^{16}$, magnetron sputtering ${ }^{17}$, etc. are the techniques often used for deposition of $\mathrm{Mg}$ doped $\mathrm{ZnO}$ thin films. Spray pyrolysis (SP) is a very simple technique which is commonly used for deposition of oxide thin films, but a few works are reported on spray deposited $\mathrm{Mg}$ doped $\mathrm{ZnO}$ thin films.

In this work, $\mathrm{Mg}$ doped $\mathrm{ZnO}$ thin films were deposited onto glass substrate by SP techniques at the substrate temperature $300^{\circ} \mathrm{C}$. Optical transmittance of $\mathrm{Mg}$ doped $\mathrm{ZnO}$ thin films were measured in the wavelength range $300-2500 \mathrm{~nm}$ by UV-VIS-NIR spectrophotometer. Absorption co-efficient, extinction co-efficient, refractive index and optical band gap of $\mathrm{Mg}$ doped $\mathrm{ZnO}$ thin films were calculated. Pure and $\mathrm{Mg}$ doped $\mathrm{ZnO}$ films were annealed at the temperature $425^{\circ} \mathrm{C}$ for 1 hour in the air. Structural properties of the annealed pure and $\mathrm{Mg}$ doped $\mathrm{ZnO}$ thin films were studied by XRD. EDX spectra of the films were also studied to confirm the presence of $\mathrm{Mg}$ in the Doped $\mathrm{ZnO}$ films. Optical and structural characteristics of some other compound semiconductors such as $\mathrm{ZnSe}{ }^{18}, \mathrm{CdTe}{ }^{19}, \mathrm{GaAs}^{20,21}$, etc. were also studied by the authors previously.

\section{Methods}

Undoped and $\mathrm{Mg}$ doped $\mathrm{ZnO}$ thin films were deposited onto chemically (with acetone and distilled water) and ultrasonically cleaned and dried glass substrate by a simple spray pyrolysis (SP) set up. Zinc acetate $\left[\mathrm{Zn}\left(\mathrm{CH}_{3} \mathrm{COO}\right)_{2}\right.$. $\left.2 \mathrm{H}_{2} \mathrm{O}\right]$ and Magnesium acetate $\left[\mathrm{Mg}\left(\mathrm{CH}_{3} \mathrm{COO}\right)_{2} .4 \mathrm{H}_{2} \mathrm{O}\right]$ were dissolved in water at room temperature to prepare the working solution. The concentrations of source materials were adjusted relatively to increase $\mathrm{Mg}$ doping between 0$40 \%$ in $\mathrm{ZnO}$. The distance between the spray nozzle and the substrate is to be maintained about $25 \mathrm{~cm}$ and the flow rate of the solution during spraying was adjusted to about 3 $\mathrm{ml} / \mathrm{min}$ and kept constant throughout the experiment. The deposition time was 7 minutes. The substrate temperature was about $300^{\circ} \mathrm{C}$ and was measured by a CopperConstantan thermocouple. The possible chemical reaction that takes place on the heated substrate as follows:

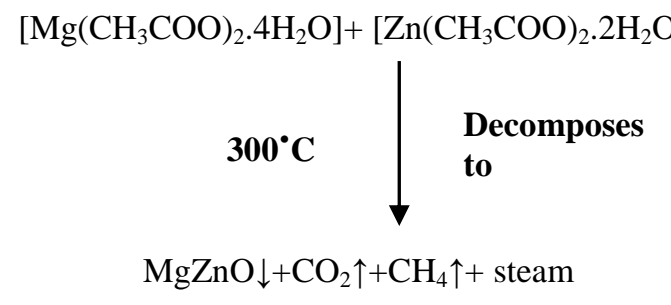

*Author for correspondence. e-mail: proggaph@gmail.com 
Optical transmittance and reflectance of undoped and $\mathrm{Mg}$ doped $\mathrm{ZnO}$ thin films were measured for photon wavelength range 300- $2500 \mathrm{~nm}$ using a Shimadzu UV-3100 UV- VISNIR spectrophotometer. The energy dispersive X-ray (EDX) analysis was done by Quanta Inspect IS50 detector which is operated in the range of $0 \mathrm{eV}$ to $30 \mathrm{keV}$.

The as deposited $\mathrm{ZnO}$ thin films were annealed at $425^{\circ} \mathrm{C}$ for one hour in air. A two-circle $(2 \theta-\theta)$ X-ray powder diffractometer, $X^{\prime}$ Pert PRO XRD Philips PW3040 with angular range $20^{\circ} \leq 2 \theta \leq 80^{\circ}$ and $\mathrm{CuK}_{\alpha}$ radiation, operated at input power of $60 \mathrm{kV}$ and $55 \mathrm{~mA}$ was used to determine the structural parameters of the annealed thin films. "X'Pert Highscore" computer software was used to study $2 \theta$ values, $\mathrm{d}$ value and full width half maximum (FWHM).

\section{Results and Discussion}

The transmission spectra of pure and $\mathrm{Mg}$ - doped $\mathrm{ZnO}$ thin films exhibit that pure $\mathrm{ZnO}$ has transmittance in the visible range of about 55\%-79\% as shown in Fig. 1. Mg doping causes decrease in the optical transmittance of $\mathrm{ZnO}$ thin films ${ }^{22}$. Transmittance of the $\mathrm{Mg}$ - doped $\mathrm{ZnO}$ thin films reduces with the increase of doping concentration between $0 \%$ and $30 \%$. But, for $40 \% \mathrm{Mg}$ doping transmittance increased up to $79 \%$. Thus transparency of the film changes due to $\mathrm{Mg}$ doping in $\mathrm{ZnO}$. Decrease in transmittance may occur due to the increase of particle size because of the progression of $\mathrm{Mg}$ in the $\mathrm{ZnO}$ thin films ${ }^{23}$.

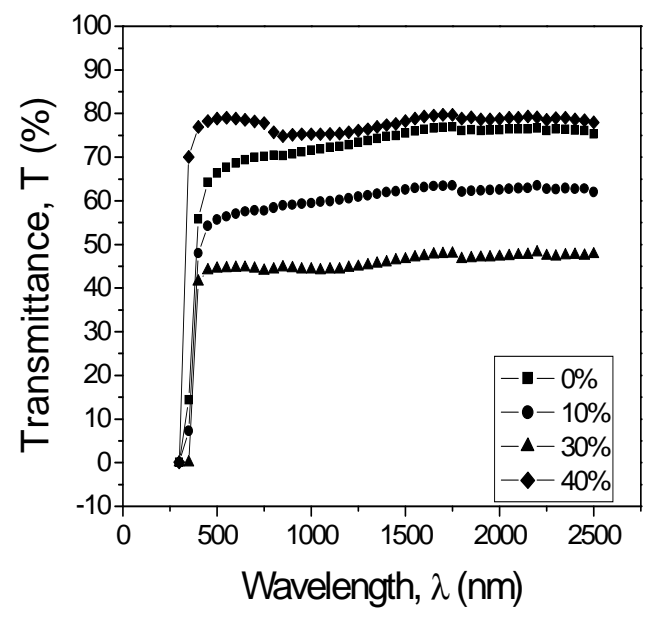

Fig.1. Transmittance versus wavelength graph for pure and Mgdoped $\mathrm{ZnO}$ thin films

The optical absorbance A is calculated from the following relation

$A=\log _{10}\left(\frac{1}{T}\right)$

Absorption co-efficient is then calculated from the relation

$\alpha=2.303\left(\frac{\mathrm{A}}{\mathrm{t}}\right)$

Here, " $t$ " represents the thickness of the films which is measured by Fizeau fringe interference method.

$\mathrm{t}=\frac{\mathrm{b}}{\mathrm{a}} \times \frac{\lambda}{2}$

Where, $\lambda$ is the wavelength of $\mathrm{Na}$ light, $\mathrm{b}$ is the fringe width and $\mathrm{a}$ is the fringe spacing.
Variation of absorption co-efficient with photon wavelength for pure and doped $\mathrm{ZnO}$ (Fig.2) shows higher absorption coefficient in the ultra violet (UV) region and it falls sharply and then becomes almost constant in the vis-NIR region. Significant increase of absorption co-efficient with increasing $\mathrm{Mg}$ content in the $\mathrm{ZnO}$ thin films indicates improvement of optical absorption in the UV region. High values of absorption co-efficient $\left(10^{6}-10^{7} \mathrm{~m}^{-1}\right)$ are found for the films, which is important as it affects the solar conversion efficiency ${ }^{24}$.

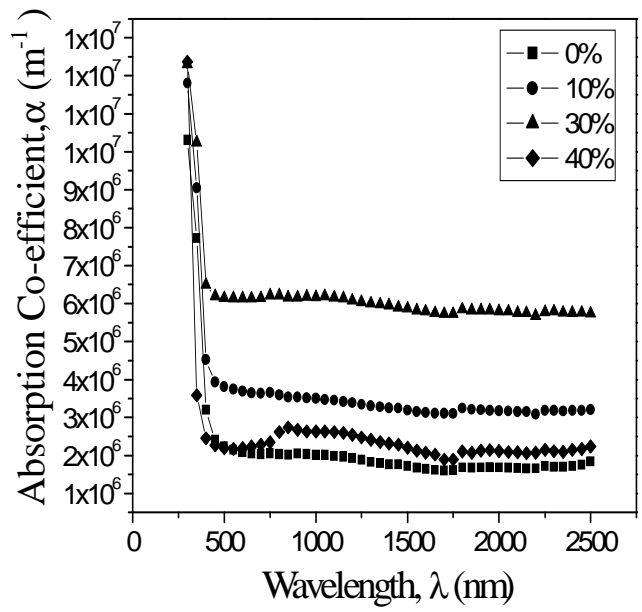

Fig. 2. Variation of absorption co-efficient with wavelength for pure and $\mathrm{Mg}$-doped $\mathrm{ZnO}$ thin films

According to Tauc formula ${ }^{25}$, absorption co-efficient $\alpha$ is related to the energy gap of a semiconductor as

$\alpha h v=C\left(h v-E_{g}\right)^{\frac{1}{2}}$

Where hv is the photon energy, $\mathrm{n}$ is an index related to the density of state $(n=1 / 2$ for direct transition and $n=2$ for indirect transition) and $E_{g}$ is the optical band gap of the semiconductor. Fig. 3 shows the plot of $(\alpha h v)^{2}$ vs photon energy, the extrapolations of the straight portion of the graphs were used to estimate the band gap of $\mathrm{ZnO}$ thin films.

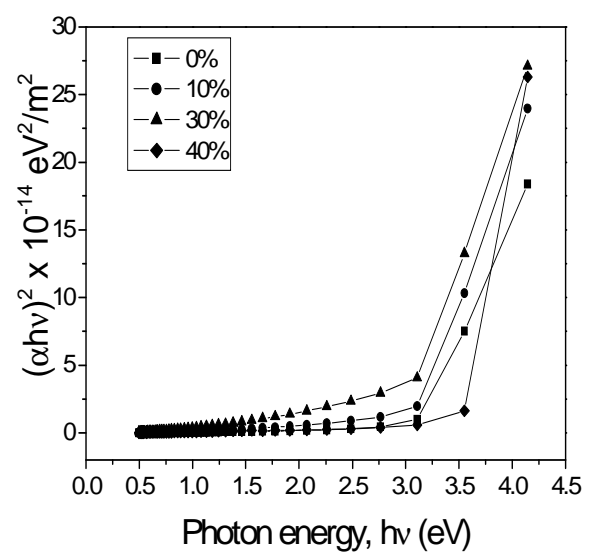

Fig. 3. $(\alpha h v)^{2}$ versus photon energy graph for pure and Mg-doped $\mathrm{ZnO}$ thin films 
A direct band gap of $3.24 \mathrm{eV}$ was found for pure $\mathrm{ZnO}$ films. The band gap increases from $3.31 \mathrm{eV}$ to $3.46 \mathrm{eV}$ with the increase of $\mathrm{Mg}$ doping concentration from $10 \%$ to $40 \%$. It is evident that $\mathrm{Mg}^{2+}$ is incorporated into the $\mathrm{ZnO}$ lattice in the $\mathrm{Mg}$ - doped $\mathrm{ZnO}$ films grown by spray pyrolysis method. The reason of band gap increase may be considered as the consequence of replacement of $\mathrm{Zn}^{2+}$ by $\mathrm{Mg}^{2+}$ in the crystal lattice. Band gap widening can be elucidated by BursteinMoss (BM) effect ${ }^{26}$. BM effect was explained for pure and doped $\mathrm{ZnO}$ thin films ${ }^{27}$ and it was found from theoretical calculations that optical band gap of $\mathrm{ZnO}$ may increase up to 0.8-0.9 eV because of moderate and heavy doping. Experimentally the blue shift in band gap is always less than the values mentioned earlier ${ }^{27}$.

Refractive index $\eta$ was calculated using the relation

$\eta=\left(\frac{1+R}{1-R}\right)+\sqrt{\frac{4 R}{(1-R)^{2}}-k^{2}}$

Where $\mathrm{k}$ is the extinction co-efficient which was calculated using the following relation

$\mathrm{k}=\frac{\alpha \lambda}{4 \pi}$

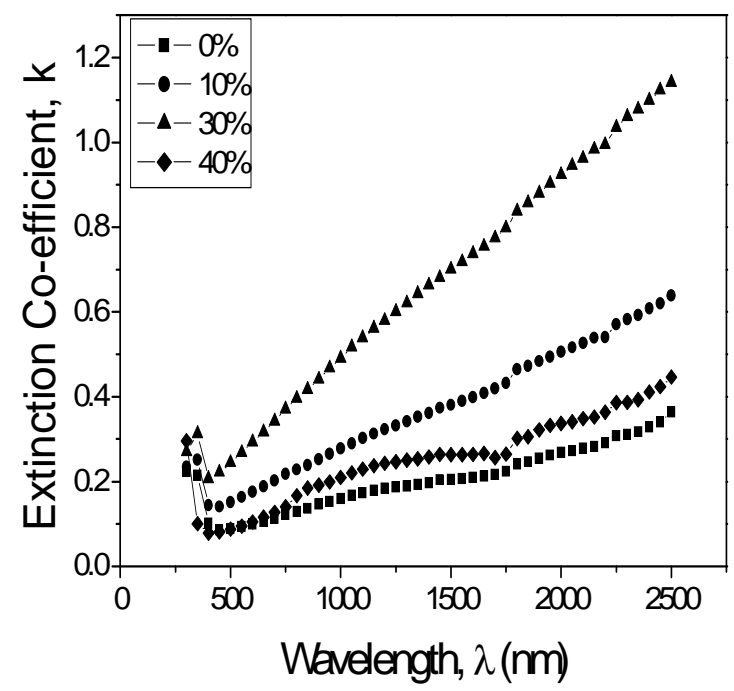

Fig.4. Variation of extinction co-efficient with wavelength for pure and $\mathrm{Mg}$-doped $\mathrm{ZnO}$ thin films

Figure.4 shows that extinction co-efficient increases with photon wavelength for the pure and $\mathrm{Mg}$ doped $\mathrm{ZnO}$ thin films. Increase of $\mathrm{Mg}$ doping in $\mathrm{ZnO}$ thin films a shows raise in extinction co-efficient, signifying the increase of absorption in the films due to $\mathrm{Mg}$ incorporation. The plot of refractive index as a function of wavelength (Fig.5) for the $\mathrm{Mg}$ doped $\mathrm{ZnO}$ thin films exhibits decrease in average value of refractive index with the increase of $\mathrm{Mg}$ concentration. It may be attributed that $\mathrm{Mg}$ doping has decreased optical density of the medium. This is the direct effect of drop in transparency of $\mathrm{ZnO}$ thin films due to $\mathrm{Mg}$ doping.

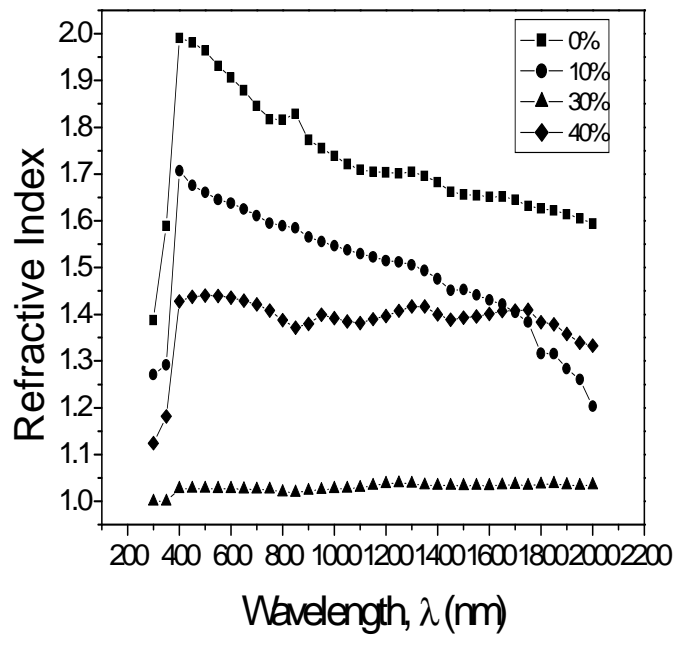

Fig. 5. Variation of refractive index with wavelength for pure and $\mathrm{Mg}$-doped $\mathrm{ZnO}$ thin films

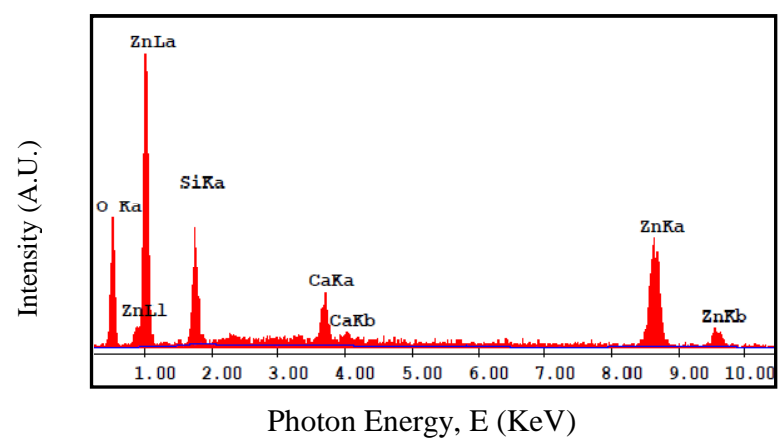

Fig. 6. EDX spectra of Pure $\mathrm{ZnO}$ thin film

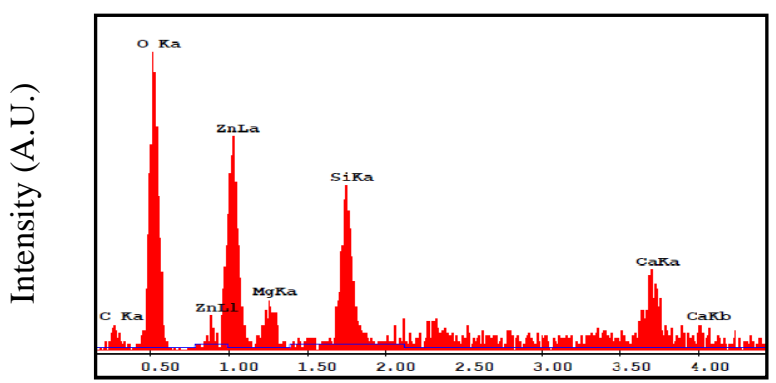

Photon Energy, E (KeV)

Fig. 7. EDX Spectra of as deposited $10 \% \mathrm{Mg}$ doped $\mathrm{ZnO}$ thin film

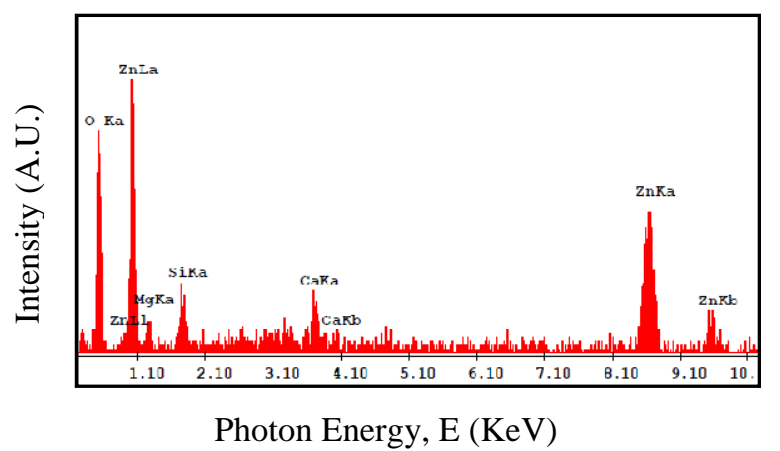

Fig. 8. EDX Spectra of as deposited $30 \% \mathrm{Mg}$ doped $\mathrm{ZnO}$ thin film 


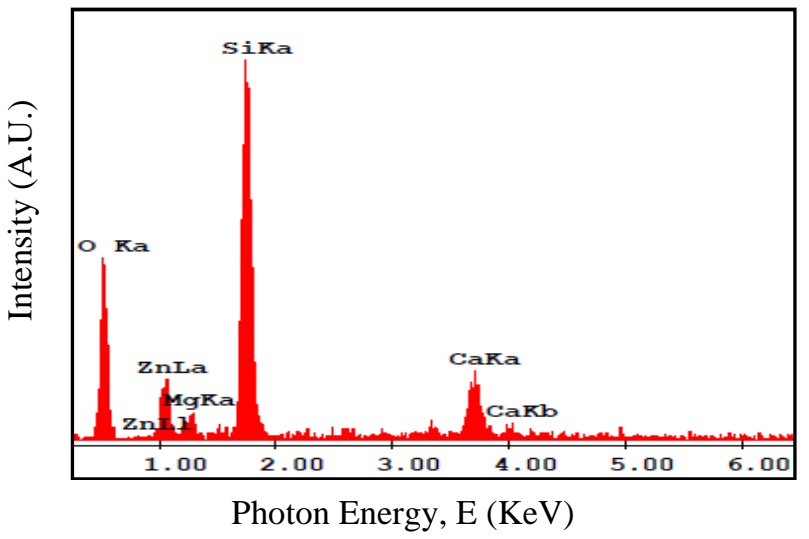

Fig. 9. EDX Spectra of as deposited $40 \% \mathrm{Mg}$ doped $\mathrm{ZnO}$ thin film

Table 1. Quantitative results of $\mathrm{Mg}$ doped $\mathrm{ZnO}$ thin films from EDX analysis

\begin{tabular}{|c|c|c|c|}
\hline $\begin{array}{c}\text { Compositions of } \\
\text { ZnO thin films }\end{array}$ & Element & Weight\% & Atom\% \\
\hline \multirow{2}{*}{ Pure } & $\mathrm{O}$ & 6.85 & 21.49 \\
\cline { 2 - 4 } & $\mathrm{Zn}$ & 84.46 & 64.83 \\
\hline \multirow{3}{*}{$10 \% \mathrm{Mg}$ doped } & $\mathrm{O}$ & 7.57 & 23.65 \\
\cline { 2 - 4 } & $\mathrm{Zn}$ & 86.24 & 66.07 \\
\cline { 2 - 4 } & $\mathrm{Mg}$ & 1.71 & 3.53 \\
\hline \multirow{3}{*}{$\begin{array}{c}30 \% \mathrm{Mg} \\
\text { doped }\end{array}$} & $\mathrm{O}$ & 12.75 & 30.40 \\
\cline { 2 - 4 } $\begin{array}{c}40 \% \mathrm{Mg} \\
\text { doped }\end{array}$ & $\mathrm{Mg}$ & 71.08 & 51.47 \\
\cline { 2 - 4 } & $\mathrm{O}$ & 25.41 & 12.77 \\
\cline { 2 - 4 } & $\mathrm{Zn}$ & 61.54 & 35.26 \\
\cline { 2 - 4 } & $\mathrm{Mg}$ & 9.31 & 13.49 \\
\hline
\end{tabular}

The quantitative results of $\mathrm{Mg}$ doped $\mathrm{ZnO}$ thin films from Table-1 show that the weight $\%$ for $\mathrm{Mg}$ increases with the increase of $\mathrm{Mg}$ doping. So, the doping concentration can be controlled precisely by the SP technique. It is observed that in all the spectra, there exist strong peak corresponding to $\mathrm{O}$. There also exist peaks for $\mathrm{Si}$ and $\mathrm{Ca}$ due to the glass substrate $\left(\mathrm{CaSiO}_{3}\right)$. The results of the EDX analysis confirm that the deposited films are very close to the nominal composition.

The structural analysis of the pure and $\mathrm{Mg}$ - doped $\mathrm{ZnO}$ films were followed by X-ray diffraction measurements. The thin films were annealed at the temperature $425^{\circ} \mathrm{C}$ for 1 hour. All the films showed hexagonal wurtzite type of polycrystalline structure with the fundamental peaks for (100), (002), (101), (102), (110), (103) and (112) planes ${ }^{23,}$ ${ }^{28}$. There were slight shifts of the peak positions in the XRD reflections, but there was no peak in the XRD pattern corresponding to $\mathrm{MgO}$ or metallic $\mathrm{Zn}$ or $\mathrm{Mg}$ or any other phase. Thus, Mg doping does not cause any remarkable change in the wurtzite structure of $\mathrm{ZnO}$. This may be due to the comparable ionic radii of $\mathrm{Zn}^{2+}$ and $\mathrm{Mg}^{2+}$ which made the substitution of $\mathrm{Zn}^{2+}$ easy with $\mathrm{Mg}^{2+29,30}$.

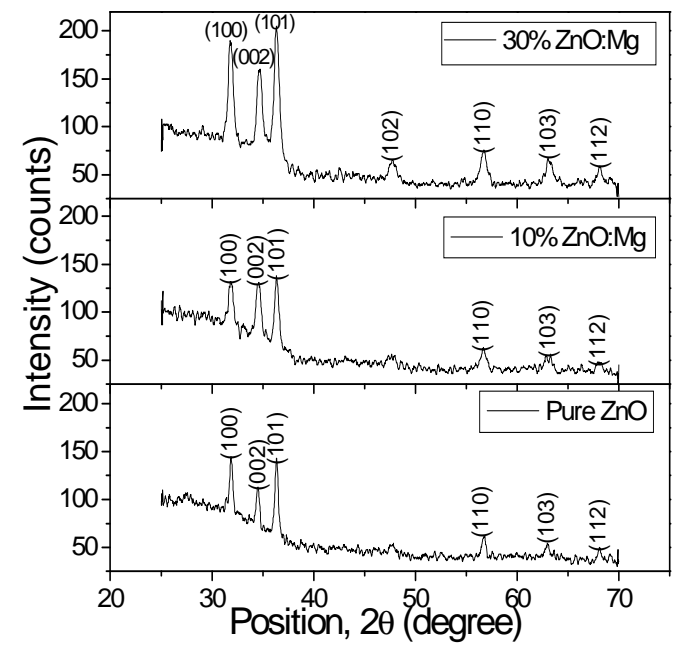

Fig. 10. XRD pattern of pure $\mathrm{ZnO}, 10 \%$ and $30 \% \mathrm{Mg}$ doped $\mathrm{ZnO}$ thin film annealed at $425^{\circ} \mathrm{C}$

The interplanar spacing for the hexagonal system is given as

$\frac{1}{\mathrm{~d}_{\mathrm{hkl}}}=\left[\frac{4}{3}\left(\frac{\mathrm{h}^{2}+\mathrm{hk}+\mathrm{k}^{2}}{\mathrm{a}^{2}}\right)+\frac{\mathrm{l}^{2}}{\mathrm{c}^{2}}\right]^{\frac{1}{2}}$

Where, $d_{\text {hkl }}$ is the inter planar spacing and it is related to the diffraction angle $\theta$ as

$\frac{1}{\mathrm{~d}_{\mathrm{hkl}}}=\frac{2 \sin \theta_{\mathrm{hkl}}}{\lambda}$

The wavelength $(\lambda)$ of X-ray was used $1.54178 \AA$ for $\mathrm{CuK}_{\mathrm{a}}$ line. The grain size, D, of the samples were determined quantitatively using the Scherrer formula ${ }^{31}$

$\mathrm{D}=\frac{\mathrm{k} \lambda}{\beta \cos \theta}$

In general, $\beta$ is obtained by measuring full width at halfmaximum (FWHM) of a diffraction peak expressed in radians. $\mathrm{k}$ is a constant $(=0.94)$. The values of $a, \mathrm{c}$ and $\mathrm{D}$ are shown in Table.2. The grain size in $\mathrm{Mg}$-doped $\mathrm{ZnO}$ thin films was less than that of pure $\mathrm{ZnO}$ thin films, whereas the lattice parameters $a$ and c were not affected much due to $\mathrm{Mg}$ doping. This is due to the fact that $\mathrm{Mg}^{2+}$ has smaller ionic radius than that of $\mathrm{Zn}^{2+}$, thus it prefers to occupy the interstitial positions and as a result unit cell becomes compact $^{28,32}$.

Table 2. Lattice parameters and grain size for pure and $\mathrm{Mg}$ doped $\mathrm{ZnO}$ thin films annealed at $425^{\circ} \mathrm{C}$ temperature for 1 hour

\begin{tabular}{|l|l|l|l|}
\hline ZnO & $\begin{array}{l}\text { Lattice } \\
\text { parameter } \\
\mathrm{c}(\AA)\end{array}$ & $\begin{array}{l}\text { Lattice } \\
\text { parameter } \\
a(\AA)\end{array}$ & $\begin{array}{l}\text { Grain size } \\
\mathrm{D}(\mathrm{nm})\end{array}$ \\
\hline Pure & 5.264 & 3.229 & 63.45 \\
\hline $\begin{array}{l}10 \% \mathrm{Mg} \\
\text { doped }\end{array}$ & 5.264 & 3.229 & 49.35 \\
\hline $\begin{array}{l}30 \% \mathrm{Mg} \\
\text { doped }\end{array}$ & 5.268 & 3.231 & 36.56 \\
\hline
\end{tabular}




\section{Conclusions}

UV-vis-NIR spectroscopic analysis of the thin films showed reduction in transmittance and refractive index values and increase in absorption co-efficient, extinction co-efficient up to $30 \%$ of $\mathrm{Mg}$ doping. Optical band gap energy increased with the increase of $\mathrm{Mg}$ doping concentration. EDX spectra and XRD pattern of the $\mathrm{ZnO}$ thin films indicated the $\mathrm{Mg}^{2+}$ substitution in the thin films. Mg doping did not affect the hexagonal wurtzite structure of the undoped $\mathrm{ZnO}$ thin films. It was found from the XRD data that grain size decreased and lattice constants were almost constant with the increase of $\mathrm{Mg}$ doping. It can be concluded that $\mathrm{Mg}$ doping can make $\mathrm{ZnO}$ more useful for optical applications due to wide band gap.

\section{Acknowledgement}

The authors express their thanks to the authorities of BUET and Atomic Energy Centre, Dhaka, Bangladesh for their support and providing necessary laboratory facilities.

\section{Reference}

1. Godbole, B, N. Badera, S. Shrivastava, D. Jain, and V. Ganesan, 2011.Growth Mechanism of ZnO Films Deposited by Spray Pyrolysis Technique. Mat. Sci. Appl.2, 643-648.

2. Nádherný, L, Z. Sofer, D. Sedmidubský, O Jankovský, and M Mikulics, 2012. ZnO Thin Films Prepared by Spray-pyrolysis Technique from Organo-metallic Precursor" Ceramics Silikáty.56 (2), 117.

3. Kumar, RA, V. Manivannan, and S. Krishnaraj, 2013. Growth and Characterization of $\mathrm{ZnO}$ Nano thin films using Spray Pyrolysis. Int. J. Res. in Pure and Appl. Phys. 3(4), 39-42.

4. Pawar, BN, S.R. Jadkar, and M.G. Takwale, 2005. Deposition and Characterization of Transparent and Conductive Sprayed ZnO: B Thin Films. J. Phys. Chem. Sol.66, 1779-1782.

5. Khan, ZR, M. S. Khan, M. Zulfequar, and M. S. Khan, 2011. Optical and Structural Properties of $\mathrm{ZnO}$ Thin Films Fabricated by Sol-Gel Method. Mat. Sci. Appl. 2, 340-345.

6. Ayouchi, R, F. Martin, D. Leinen, and J.R. Ramos-Barrado, 2003. Growth of Pure $\mathrm{ZnO}$ Thin Films Prepared by Chemical Spray Pyrolysis on Silicon. J. Cryst. Growth 247, 497-504.

7. Zhao, L, J. Lian, Y. Liu, and Q. Jiang, 2006. Structural and Optical Properties of ZnO Thin Films Deposited on Quartz Glass by Pulsed Laser Deposition. Appl. Surface Sci. 252, 8451-8455.

8. Tripathi, B, M. Patel, A. Ray, and M. Kumar, 2013. Influence of Optical Properties of ZnO Thin Films Deposited by Spray Pyrolysis and rf Magnetron Sputtering on The Output Performance of Silicon Solar Cell. IOP Conf. Ser. Mat. Sci. Eng. 43, 012002(1) - 012002(5).

9. Das, SC, R. J. Green, J. Podder, T. Z. Regier, G. S. Chang, and A. Moewes, 2013. Bang Gap Tuning in ZnO Through Ni Dopping via Spray Pyrolysis. J. Phys. Chem. C 117, 1274512753.

10. Kim TH, J.J. Park, S.H. Nam, H.S. Park, N.R. Cheong, J.K. Songa, and S.M. Park, 2009. Fabrication of Mg-doped ZnO Thin Films by Laser Ablation of Zn:Mg Target. Appl. Surf. Sci. 255, 5264-5266.

11. Fang, TH, and S. H. Kang, 2010. Preparation and Characterization of $\mathrm{Mg}$-doped $\mathrm{ZnO}$ Nanorods. J. Alloys. Comp. 492(1-2), 536-542.
12. Ghosh, M, and A. K. Raychaudhuri, 2011. Optical Properties of Mg-Substituted $\mathrm{ZnO}$ Nanoparticles Obtained by Solution Growth. Trans. Nanotech. 10 (3), 555-559.

13. El-Shaer, A, A. Che Mofor, A. Bakin, M. Kreye, and A. Waag, 2005. High-Quality ZnO Layers Grown by MBE on Sapphire. Superlatt. Microstruct. 38(4-6), 265-271.

14. Huan, L, L. Feng, J. Zhai, L. Jiang, and D. Zhu, 2004. Reversible Wettability of a Chemical Vapor Deposition Prepared ZnO Film Between Superhydrophobicity and Superhydrophilicity. Langmuir 20 (14), 5659-5661.

15. Chia, CH, Y. J. Lai, T. C. Han, J. W. Chiou, Y. M. Hu, and W. C. Chou, 2010. High-excitation Effect on Photoluminescence of Sol-gel ZnO Nanopowder. Appl. Phys. Lett. 96, 081903.

16. Madahi, P, N. Shahtahmasebi, A. Kompany, M. Mashreghi, M. M. Bagheri-Mohagheghi, and A. Hosseini, 2011. Deposition and Characterization of $\mathrm{Mg}$ doped $\mathrm{ZnO}$ Thin Films: the study of antibacterial properties. Phys. Scripta 84, 035801- 035805 .

17. Huafu, Z, Y. Shugang, L. Hanfa, and Y. Changkun, 2011. Preparation and Characterization of Transparent Conducting ZnO:W Films by DC Magnetron Sputtering. J. Semicond. 32(4), 043002-043006

18. Islam, A, C. Das, S. Choudhury, M. Sharmin, and T. Begum, 2014. Structural and Optical Characterization of Vacuum Evaporated Zinc Selenide Thin Films. Euro. Sci. J. 10(15), 241-253.

19. Mandal, M, S. Choudhury, C. Das, and T. Begum. 2014. Substrate Temperature Dependent Optical and Structural Properties of Vacuum Evaporated CdTe Thin Films. Euro. Sci. J. 10(3), 442-455.

20. Das, C, S. Choudhury, T. Begum, J. Begum, 2013. Effect of Thickness on the Optical Properties of GaAs Thin Films. $J$. Bangladesh Acad. Sci. 37(1), 83-91.

21. Sharmin, M., S. Choudhury, N. Akhtar, and T. Begum. 2012. Optical and Transport Properties of p-type GaAs. J. Bangladesh Acad. Sci. 36(1): 97-108.

22. $\mathrm{Xu}, \mathrm{L}$, and $\mathrm{X}$. Li, 2010. Influence of Fe- doping on the Structural and Optical Properties of ZnO Thin Films Prepared by Sol-gel Method. J. Cryst. Growth. 312(6), 851-855.

23. Salina, M, R. Ahmad, A. B. Suriani, and M. Rusop, 2012. Bandgap Alteration of Transparent Zinc Oxide Thin Film with Mg Dopant. Trans. Electr. Electron. Mater. 13(2), 64-68.

24. Hussain, KMA, J. Podder, D.K Saha, and M. Ichimura, 2012. Structural, Electrical and Optical Characterization of $\mathrm{CuInS}_{2}$ Thin Films Deposited by Spray Pyrolysis. Ind. J. Pure Appl. Phys. 50, 117-122.

25. Wood, DL, and J. S. Tauc, 1972. Weak Absorption Tails in Amorphous Semiconductors. Phys. Rev. B 5, 3144-3151.

26. Burstein, E, 1953. Anomalous Optical Absorption Limit in InSb. Phys. Rev. 93,632-633.

27. Ziabari, AA, and S.M. Rozati, 2012. Carrier Transport and Bandgap Shift in n-type Degenerate ZnO Thin Films: The Effect of Band Edge Nonparabolicity. Physica B. 407, 45124517.

28. Shayesteh, SF, and A. A. Dizgah, 2013.Effect of Doping and Annealing on the Physical Properties of $\mathrm{Mg}$ Doped $\mathrm{ZnO}$ Nanoparticles. PRAMANA J. Phys. 81(2), 319-330. 
29. Zhuang, H, J. Wang, H. Liu, J. Li, and P. Xu, 2011. Structural and Optical Properties of $\mathrm{ZnO}$ Nanowires Doped with Magnesium, Acta Phys. Polonica A.119 (6), 819-823.

30. Singh, J, M.S.L. Hudson, S.K. Pandey, R.S. Tiwari, and O.N. Srivastava, 2012.Structural and Hydrogenation Studies of $\mathrm{ZnO}$ and $\mathrm{Mg}$ Doped $\mathrm{ZnO}$ Nanowires. Int. J. Hydrogen Energy.37, 3748-3754.

31. Warren, BE, 1969. X-ray Diffraction. Addision-Wesly Publishing Co., London.

32. Agrawal, A, T. A. Dar, and P. Sen, 2013. Structural and Optical Studies of Magnesium Doped Zinc Oxide Thin Films. J. Nano- Electron. Phys. 5(2), 02025(1)-02025(3). 